\title{
Introduction to the XXVI Bárány Society Meeting
}

\section{The Bárány Society}

We celebrate the Bárány Society's $50^{\text {th }}$ anniversary this year. The Bárány Society was founded in 1960 to honor the memory of the late Robert Bárány, who was professor of Oto-rhinolaryngology at the University of Uppsala, Sweden, from 1926 to 1936.

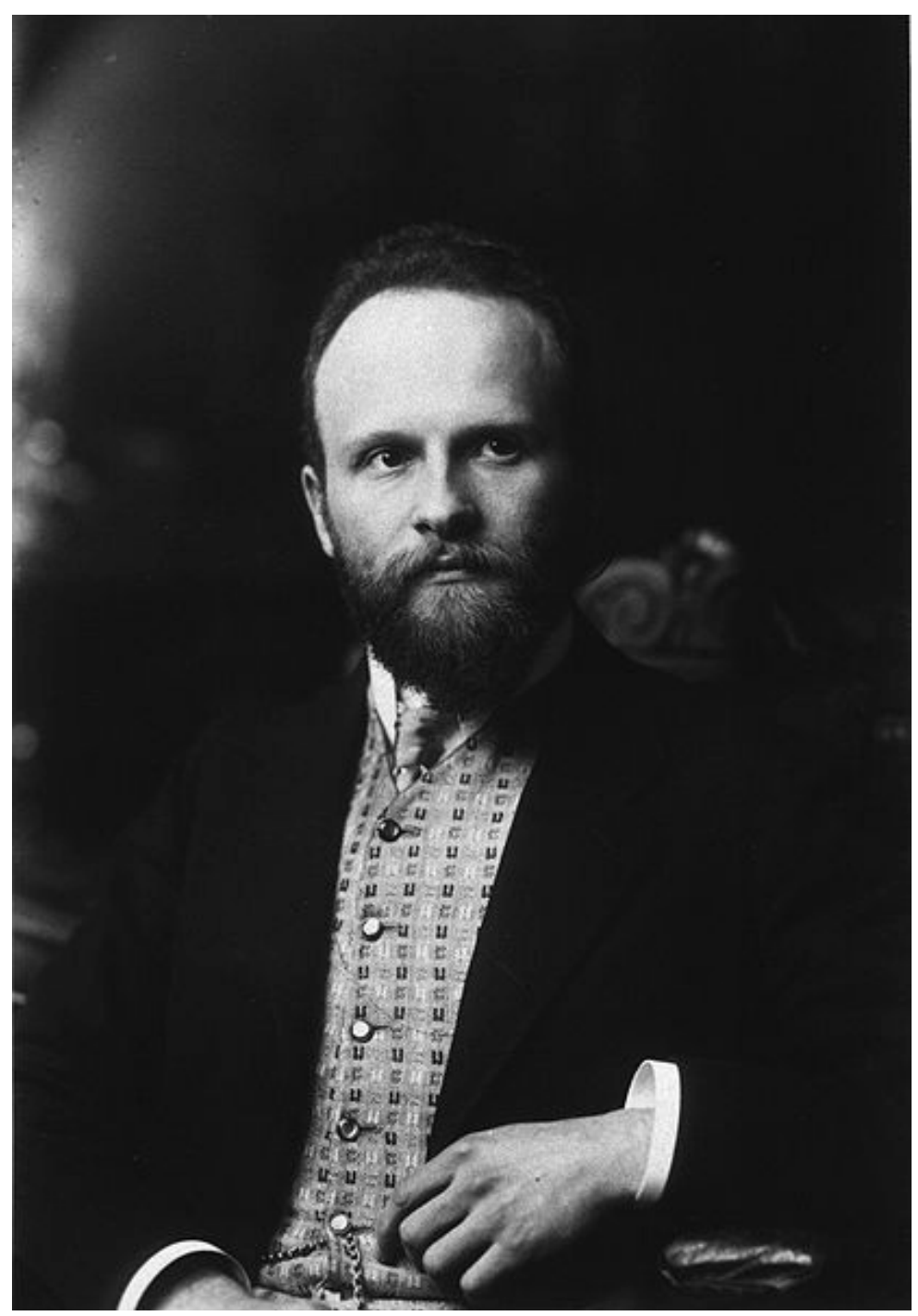


Bárány was awarded the Nobel Prize for his work in the field of vestibular physiology and pathology in 1914, but at that time he was held captured in a Russian prisoner-of-war camp. Following the personal intervention of Prince Carl of Sweden on behalf of the Red Cross, he was released in 1916 and was presented with the Nobel Prize by the King of Sweden in Stockholm that year.

The Bárány Society aims to develop contacts and partnership between scientists and clinicians involved in the research and treatment of vestibular system function and disorders.

The current president of the Bárány Society is Professor Matti Anniko.

It is with great enthusiasm and respect that we host the XXVI Bárány Society Meeting in Reykjavik this year. Our task was to make this meeting of a high scientific standard and to make this summer visit, including the Reykjavik Festival and Iceland's wonders of nature, a time to remember.

The scientific part of the congress, documented in this issue of the Journal of Vestibular Research, reflects almost all aspects of vestibular science with contributions from scientists from all over the world.

On the behalf of all involved I warmly welcome you to Reykjavik for the XXVI Bárány Society Meeting.

Hannes Petersen

\section{Organizing Committee}

Hannes Petersen, Iceland

Måns Magnusson, Sweden

Lloyd Minor, United States of America

Herman Kingma, The Netherlands

Adolfo M. Bronstein, United Kingdom

Kathleen E. Cullen, Canada

Helen Cohen, United States of America

Ian Curthoys, Australia

Philippe Perrin, France

\section{Scientific Committee}

Hannes Petersen, Iceland

Måns Magnusson, Sweden

Sigurður Stefánsson, Iceland

Friðrik Guðbrandsson, Iceland 


\section{Acknowledgement}

The organizers sincerely thank the following companies and institutions for their support:

\section{Sponsors}

Actavis

GlaxoSmithKline

Icepharma

Icelandic Glacial Spring Water

The Federation of Icelandic Fishing Vessel Owners (LIUU)

The Ministry of Education, Science and Culture

The Ministry of Health

University of Iceland

Vistor

\section{Exhibitors}

AMTI Force and Motion

GN Otometrics A/S

Dr. E. Horn-Autronic GmbH

Interacoustics $\mathrm{A} / \mathrm{S}$

VestiCure GmbH 